\title{
Synchronous presentation of acute acalculous cholecystitis and appendicitis: a case report
}

\author{
Shaheel M Sahebally', John P Burke ${ }^{1 *}$, Niamh Nolan² and Amir Latif ${ }^{1}$
}

\begin{abstract}
Introduction: Acute acalculous cholecystitis is traditionally associated with elderly or critically ill patients.

Case presentation: We present the case of an otherwise healthy 23-year-old Caucasian man who presented with acute right-sided abdominal pain. An ultrasound examination revealed evidence of acute acalculous cholecystitis. A laparoscopy was undertaken and the dual pathologies of acute acalculous cholecystitis and acute appendicitis were discovered and a laparoscopic cholecystectomy and appendectomy were performed.

Conclusion: Acute acalculous cholecystitis is a rare clinical entity in young, healthy patients and this report describes the unusual association of acute acalculous cholecystitis and appendicitis. A single stage combined laparoscopic appendectomy and cholecystectomy is an effective treatment modality.
\end{abstract}

\section{Introduction}

Acute acalculous cholecystitis (AAC) is rare clinical entity traditionally associated with elderly patients with extensive co-morbidities or critically ill patients, such as those with burns or who have sustained trauma. We present a case of an otherwise healthy 23-year-old man who presented with acute right sided abdominal pain and had ultrasonographic evidence of both AAC and acute appendicitis.

\section{Case presentation}

A 23-year-old unemployed Caucasian man presented to our Emergency Department with a twelve-hour history of severe right upper and lower quadrant pain. This pain originated in his epigastrium and was associated with nausea, multiple episodes of non-bilious vomiting and anorexia. His background history was unremarkable. He was on no regular medications, did not smoke and was a social drinker. On physical examination, he had a normal pulse and blood pressure but was pyrexic $\left(38.5^{\circ} \mathrm{C}\right)$. An abdominal examination revealed tenderness in his right upper quadrant and right iliac fossa, guarding and rebound tenderness. Rovsing, obturator and psoas signs were negative. Laboratory investigations revealed an elevated white cell count of $14.3 \times 10^{9} / \mathrm{L}$, and slightly

\footnotetext{
* Correspondence: drjohnpburke@yahoo.ie

${ }^{1}$ Department of General Surgery, St Columcille's Hospital, Loughlinstown,

County Dublin, Ireland

Full list of author information is available at the end of the article
}

deranged liver function tests, namely a total bilirubin of $54 \mu \mathrm{mol} / \mathrm{L}$ and aspartate aminotransferase of $39 \mathrm{U} / \mathrm{L}$ with normal renal function and electrolytes. A dipstick of his urine showed 1+ bilirubin, 1+ blood and 4+ ketones. His Alvarado score was 10, consistent with appendicitis [1].

An ultrasound of his abdomen and pelvis revealed an inflamed, thick-walled gallbladder but no evidence of gallstones (Figure 1A). His appendix could not be visualised and there was no free fluid in the pelvis (Figure 1B). A diagnostic laparoscopy was performed, which revealed a gangrenous gallbladder with omental wrapping (Figure 1C) and an acutely inflamed appendix with thickened mesentery (Figure 1D). A combined laparoscopic cholecystectomy and appendectomy was performed. Histological examination of the resected gallbladder and appendix showed acute cholecystitis with diffuse inflammation of the gallbladder wall, edema and necrosis with extensive venous thrombi but no evidence of gallstones (Figure 1E) along with acute appendicitis (Figure 1F). Microbiological culture of the gallbladder bile revealed no bacterial growth. Our patient's postoperative course was unremarkable and he was discharged home two days later. At the latest follow-up, four months after surgery, he is well and without complaint.

\section{Discussion}

AAC is a well-recognized but poorly understood clinical entity. Traditionally, it occurs in elderly patients with 


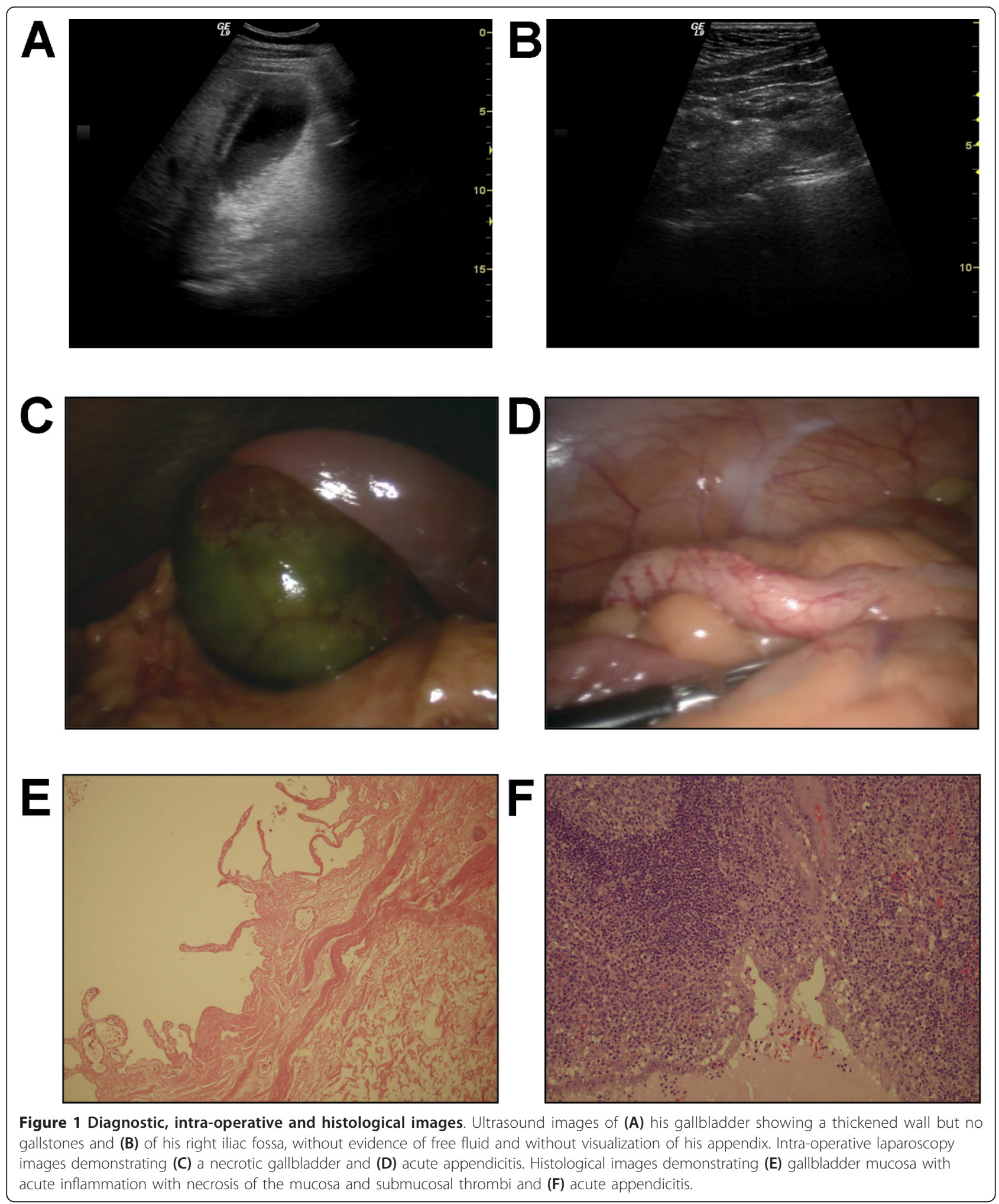

chronic debilitating disease or patients with critical illness, typically trauma or major burn injury. Whilst early case series associated AAC exclusively with critical illness [2], more recent reports demonstrate increasing de novo presentation of AAC in the absence of acute illness [3] and even in young, otherwise healthy patients without any predisposing factors [4]. The age of onset of $\mathrm{AAC}$ has been reported to be most commonly in the 
sixth decade [3]. The commonest postulated etiologies of AAC are bile stasis resulting in a change in bile composition, sepsis and ischemia [5]. In critically ill patients, AAC results from gallbladder ischemia, which may be secondary to shock due to hypovolemia or sepsis.

It has previously been noted that a hyperbilirubinemia occurs in acute appendicitis [6]. It has been proposed that appendicitis associated hyperbilirubinemia is due to bacterial translocation into the portal venous system, leading to altered bilirubin excretion. This, in combination with sepsis, may have precipitated AAC in our patient.

\section{Conclusion}

AAC is a rare clinical entity in young, healthy patients and to the best of our knowledge, this represents the first report of AAC associated with acute appendicitis. A single stage combined laparoscopic appendectomy and cholecystectomy was an effective treatment modality in this case, although the timing of surgery for acute cholecystitis remains controversial, with some surgeons opting for interval cholecystectomy which carries a lesser risk of conversion to an open procedure or damage to the common bile duct, whereas other surgeons prefer early cholecystectomy to avoid failure of conservative management and to prevent disease recurrence. Surgical management of AAC in the end depends on the severity of the disease, physical status of the patient and the laparoscopic skill of the surgeon.

\section{Consent}

Written informed consent was obtained from the patient for the publication of this case report and accompanying images. A copy of the written consent is available for review by the Editor-in-Chief of this journal.

\section{Author details}

'Department of General Surgery, St Columcille's Hospital, Loughlinstown, County Dublin, Ireland. ²Department of Histopathology, St Columcille's Hospital, Loughlinstown, County Dublin, Ireland.

\section{Authors' contributions}

SS compiled and analyzed the patient's data and wrote the initial draft. JPB corrected the draft and assisted in the patient's operation. NN performed the histological examination of the resected gallbladder and appendix and contributed to writing the manuscript. AL performed the operation and reviewed the final manuscript. All authors read and approved the final manuscript.

\section{Competing interests}

The authors declare that they have no competing interests.

Received: 9 June 2011 Accepted: 14 November 2011

Published: 14 November 2011

\section{References}

1. Alvarado A: A practical score for the early diagnosis of acute appendicitis. Ann Emerg Med 1986, 15(5):557-564.

2. Fox MS, Wilk PJ, Weissmann HS, Freeman LM, Gliedman ML: Acute acalculous cholecystitis. Surg Gynecol Obstet 1984, 159(1):13-16.
3. Savoca PE, Longo WE, Zucker KA, McMillen MM, Modlin IM: The increasing prevalence of acalculous cholecystitis in outpatients. Results of a 7-year study. Ann Surg 1990, 211(4):433-437.

4. Parithivel VS, Gerst PH, Banerjee S, Parikh V, Albu E: Acute acalculous cholecystitis in young patients without predisposing factors. Am Surg 1999, 65(4):366-368,

5. Huffman JL, Schenker S: Acute acalculous cholecystitis: a review. Clin Gastroenterol Hepatol 2010, 8(1):15-22.

6. Estrada JJ, Petrosyan M, Barnhart J, Tao M, Sohn H, Towfigh S, Mason RJ: Hyperbilirubinemia in appendicitis: a new predictor of perforation. $J$ Gastrointest Surg 2007, 11(6):714-718.

doi:10.1186/1752-1947-5-551

Cite this article as: Sahebally et al: Synchronous presentation of acute acalculous cholecystitis and appendicitis: a case report. Journal of Medical Case Reports 2011 5:551.

\section{Submit your next manuscript to BioMed Central and take full advantage of:}

- Convenient online submission

- Thorough peer review

- No space constraints or color figure charges

- Immediate publication on acceptance

- Inclusion in PubMed, CAS, Scopus and Google Scholar

- Research which is freely available for redistribution 